\title{
First detection of Echinococcus multilocularis in dogs in a highly endemic area of Poland
}

\author{
Jacek Karamon ${ }^{1}$, Małgorzata Samorek-Pieróg ${ }^{1}$, Maciej Kochanowski ${ }^{1}$, Joanna Dąbrowska ${ }^{1}$, Jacek Sroka ${ }^{1}$, \\ Elżbieta Gołąb ${ }^{2}$, Gérald Umhang ${ }^{3}$ and Tomasz Cencek ${ }^{1}$
}

\author{
${ }^{1}$ Department of Parasitology and Invasive Diseases, National Veterinary Research Institute, Puławy, Poland; \\ ${ }^{2}$ Department of Parasitology, National Institute of Public Health - National Institute of Hygiene, Warsaw, Poland; \\ ${ }^{3}$ French Agency for Food, Environmental and Occupational Health \& Safety (ANSES), Nancy Laboratory for Rabies and Wildlife, \\ Wildlife Surveillance and Eco-epidemiology, National Reference Laboratory for Echinococcus spp., Malzéville, France
}

\begin{abstract}
The aim of the investigation was to estimate the epizootic situation concerning infection by the cestode Echinococcus multilocularis Leuckart, 1863 in dogs (Canis lupus familiaris Linnaeus) from a Polish region where this parasite is highly prevalent in red foxes. Faecal samples $(\mathrm{n}=148)$ were collected from rural dogs in Podkarpackie Province. Samples were examined through nested PCR (for E. multilocularis), multiplex PCR (E. multilocularis, species of Taenia Linnaeus, 1758) and PCR [E. granulosus (Batsch, 1786)]. Specific products were sequenced. Faeces were also examined coproscopically. In samples from two dogs (1.4\%), there were positive PCR results for E. multilocularis. Taenia-specific PCR products were found in nine dogs (6.1\%). Sequencing identified Taenia serialis (Gervais, 1847), T. hydatigena Pallas, 1766, T. pisiformis (Bloch, 1780) and Hydatigera taeniaeformis (Batsch, 1786). One sample $(0.7 \%)$ was identified as Mesocestoides litteratus (Batsch, 1786). All samples were negative for E. granulosus with PCR. Taking into account coproscopic and PCR results, $28 \%$ of dogs were infected with helminths ( $8 \%$ with tapeworms). It should be stressed that one of the infected with E. multilocularis dogs shed eggs of the Taenia type and had a habit of preying on rodents. This investigation revealed the presence of E. multilocularis in dogs for the first time in Poland.
\end{abstract}

Keywords: alveolar echinococcosis, Echinococcus granulosus, Taenia, PCR, faeces

Echinococcus multilocularis Leuckart, 1863 is a tapeworm, the larval forms of which cause alveolar echinococcosis in humans. One of the most dangerous zoonotic diseases, it can be fatal if untreated. Humans only play the role of a non-specific accidental intermediate host, certain rodent species being specific intermediate hosts in the parasite's life cycle. The principal final host is the red fox, Vulpes vulpes (Linnaeus). Echinococcus multilocularis is widespread in the red fox population, so this species is mainly responsible for environmental contamination by spreading the parasite's infective eggs via their faeces (Hegglin and Deplazes 2013).

Among domesticated animals, this function can also be carried out by dogs (Canis lupus familiaris Linnaeus) and even cats (Felis catus Linnaeus). Unlike cats, in which infection is very limited (Kapel et al. 2006, Thompson et al. 2006, Umhang et al. 2015), the dog is an adequate host for the development of the mature forms of E. multilocularis: the time and intensity of the excretion of tapeworm eggs by infected dogs were comparable to the results obtained for foxes and raccoon dogs (Kapel et al. 2006).
The role of dogs as potential hosts of E. multilocularis is increasing as globalisation develops, facilitating movements over long distances. It creates new opportunities for spreading this infection to areas where it is almost impossible for the parasite to be brought through free-living hosts, such as islands. In order to control this threat, the EC Commission adopted Regulation No. 1152/2011, which defines rules on transporting dogs to countries known to be free of this infection (currently four Member States, namely Ireland, the United Kingdom, Malta and Finland).

However, with the exception of a single study (Machnicka-Rowińska et al. 2002) that gave negative results, investigations into the prevalence of this infection in dogs have not been conducted in Poland, a country where E. multilocularis is highly prevalent in foxes. In 2009-2013, the mean prevalence rate was $17 \%$, but there were areas in the east of the country where prevalence reached $50 \%$ (Karamon et al. 2014). It was shown to have been persisting at a high level for several years (Karamon et al. 2015), which indicates a high risk for people living in these areas. This is why Podkarpackie Province - which is characterised by one of

Address for correspondence: J. Karamon, Department of Parasitology and Invasive Diseases, National Veterinary Research Institute, Al. Partyzantow 57, 24-100 Puławy, Poland. Phone: +48 818893040; Fax: +48 818862595; E-mail: j.karamon@piwet.pulawy.pl 
the highest percentages of infected foxes (47\%) - was selected to study the infection of dogs with E. multilocularis. The aim was to evaluate the prevalence of $E$. multilocularis in dogs from areas where the parasite is highly prevalent in red foxes.

\section{MATERIALS AND METHODS}

Dogs. Samples of faeces were collected from 148 rural dogs originating from four districts in Podkarpackie Province (south-eastern Poland) between March and May 2015. Most of the samples were obtained from Strzyżów District $(\mathrm{n}=125)$, and the others from three bordering districts: Krosno $(\mathrm{n}=11)$, Rzeszów ( $=9)$ and Ropczyce-Sędziszów $(n=3)$. Samples were obtained from pet and guard dogs in villages, farms and rural areas of small towns. Fresh samples of faeces were collected by veterinarians during their visits to individual locations for an anti-rabies vaccination campaign in cooperation with dog owners who provided the samples. Up to $48 \mathrm{~h}$ after collection, each sample was first frozen $\left(-20^{\circ} \mathrm{C}\right)$ by veterinarians and then sent in batches to the National Veterinary Research Institute (NVRI). Owners were asked to fill in questionnaires including information on deworming (last treatment, kind of drug) and their dogs' habits as to preying on rodents.

In the NVRI laboratory, faeces were frozen for at least seven days at $-80^{\circ} \mathrm{C}$ before examination for safety reasons. DNA from faecal samples was extracted with the QIAamp ${ }^{\circledR}$ DNA Stool Mini Kit (Qiagen, Hilden, Germany) according to the manufacturer's protocol for larger volumes of stool. In this protocol, $1 \mathrm{~g}$ of sample was first diluted $(1: 10)$ in lysing buffer and homogenised. Next, $2 \mathrm{ml}$ of mixture was used in the following extraction stages. DNA samples were examined by multiplex PCR with the use of primers to detect E. multilocularis and species of Taenia Linnaeus, 1758 (Trachsel et al. 2007). Additionally, each sample was tested by nested PCR as described by Dinkel et al. (1998) with some modifications (Karamon et al. 2012) to identify E. multilocularis. Moreover, samples were examined to detect Echinococcus granulosus (Batsch, 1786) by PCR according to Abbasi et al. (2003) with the use of only one pair of primers, Eg1121a and Eg1122a. Each DNA sample was examined by PCR using two variants - undiluted and 1:10 diluted - to minimise the possibility of inhibition (Karamon 2014).

The E. multilocularis and Taenia spp. positive PCR products were sequenced. Samples for sequencing were purified using Sephadex G-50 columns. Sequencing was performed using a BigDye ${ }^{\mathrm{TM}}$ Terminator v3.1 Cycle Sequencing kit (Applied Biosystems, Foster City, USA) on an ABI3730xl Genetic Analyzer (Applied Biosystems). The sequenced data were analysed and compared to the GenBank collection using BLAST searchers.

A part of each fecal sample (1-2 g) was examined by flotation (McMaster method according to Raynaud's modification - Raynaud 1970) to detect parasite eggs and oocysts.

People. Members of a family whose dog was infected with E. multilocularis were referred by family doctor to a serological diagnostic tests due to the potential risk of infection. Two IgG ELISA tests (Bordier Affinity Products S.A., Crissier, Switzerland) for the serological diagnosis of human echinococcosis were used: an E. granulosus ELISA and an E. multilocularis ELISA. The tests were carried out according to the manufacturer's in-

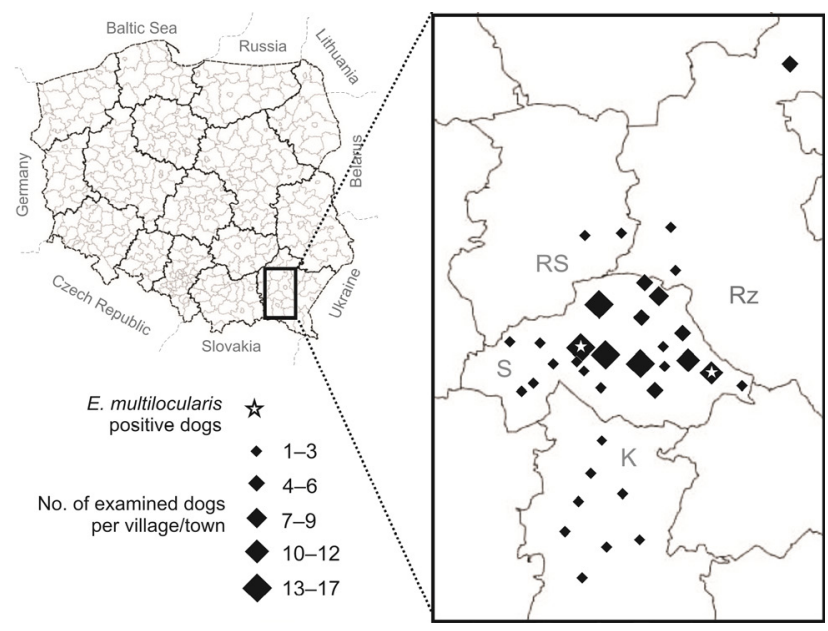

Fig. 1. Distribution of the location of collected faecal samples and location of dogs (Canis lupus familiaris Linnaeus) positive for E. multilocularis Leuckart, 1863. (Districts: K - Krosno, RS - Ropczyce-Sędziszów, Rz - Rzeszów, S - Strzyżów, )

structions in the Diagnostics Laboratory of the Department of Medical Parasitology NIPH-NIH, Warsaw.

Red foxes. In the area where the dogs were sampled, the prevalence of E. multilocularis in foxes was estimated by necropsy to confirm the high prevalence observed previously. Fifty nine foxes were shot by hunters from October 2014 to January 2015 in the area covering most of the locations of the dogs studied, i.e. Strzyżów and Krosno districts. The small intestines were examined after being frozen for at least seven days at $-80^{\circ} \mathrm{C}$ before examination for safety reasons. All the samples of intestines were examined using the sedimentation and counting technique (Hofer et al. 2000, OIE 2008).

\section{Statistical analysis}

Differences in prevalence between dogs grouped according to questionnaire parameters (dewormed/untreated or preying/not preying) were tested using V-square tests $(\mathrm{P}<0.05)$ with Statistica 9.1 (StatSoft Inc., Tulsa, USA).

\section{RESULTS}

Dogs. In samples from two dogs (from Strzyżów District), PCR results were positive for E. multilocularis (prevalence 1.4\%) (Fig. 1). In one positive dog, a specific product was detected by both PCRs (nested PCR and multiplex PCR) only in diluted DNA (1 : 10 dilution). However, a positive result was found in the other dog only by using nested PCR and only in an undiluted isolate. The amplicons obtained were sequenced and then compared to the GenBank database, confirming that the causative agent was E. multilocularis in both cases.

Multiplex PCR products of $267 \mathrm{bp}$ were found in ten dogs. A comparison of sequences with those in the GenBank database identified nine samples $(6.1 \%)$ as Taenia spp.: four samples contained Taenia serialis (Gervais, 1847), two T. hydatigena Pallas, 1766, two T. pisiformis (Bloch 1780), one Hydatigera taeniaeformis (Batsch, 1786) and one sample Mesocestoides litteratus (Batsch, 1786). None of the dogs were coinfected with E. multiloc- 
Table 1. Echinococcus multilocularis Leuckart, 1863 and other parasites in dog (Canis lupus familiaris Linnaeus) faeces detected by PCR and coproscopy.

\begin{tabular}{|c|c|c|c|c|c|c|c|c|c|c|c|c|}
\hline & \multicolumn{4}{|c|}{ PCR } & \multicolumn{6}{|c|}{ Coproscopy } & \multicolumn{2}{|c|}{$\begin{array}{c}\text { Coproscopy and } \\
\text { PCR }\end{array}$} \\
\hline & $\begin{array}{c}\text { E. multi- } \\
\text { locularis } \\
\text { Leuckart, } \\
1863\end{array}$ & $\begin{array}{c}\text { E. gran- } \\
\text { ulosus } \\
\text { (Batsch, } \\
1786)\end{array}$ & $\begin{array}{c}\text { Taenia } \\
\text { Linnaeus, } \\
1758\end{array}$ & $\begin{array}{c}\text { Meso- } \\
\text { cestoides } \\
\text { litteratus } \\
\text { (Batsch, } \\
\text { 1786) }\end{array}$ & $\begin{array}{l}\text { Taeniidae } \\
\text { Ludwig, } \\
1886\end{array}$ & $\begin{array}{c}\text { Trichuris } \\
\text { Roederer, } \\
1761 / \\
\text { Capillaria } \\
\text { Zeder, } \\
1800\end{array}$ & $\begin{array}{c}\text { Toxocara } \\
\text { Stiles et } \\
\text { Hassal, } \\
1905\end{array}$ & $\begin{array}{l}\text { Toxas- } \\
\text { caris } \\
\text { leonina } \\
\text { (von } \\
\text { Linstow } \\
1902 \text { ) }\end{array}$ & $\begin{array}{c}\text { Cystoi- } \\
\text { sospora } \\
\text { Frenkel, } \\
1977\end{array}$ & $\begin{array}{c}\text { Helminths } \\
\text { together }\end{array}$ & $\begin{array}{c}\text { Tape- } \\
\text { worms }\end{array}$ & $\begin{array}{c}\text { Helminths } \\
\text { together }\end{array}$ \\
\hline $\begin{array}{l}\text { Number of } \\
\text { positive }\end{array}$ & 2 & 0 & 9 & 1 & 4 & 26 & 22 & 3 & 6 & 36 & 12 & 41 \\
\hline $\begin{array}{l}\text { Prevalence } \% \\
(95 \% \text { CI })\end{array}$ & $\begin{array}{c}1.4 \\
(0.4-4.8)\end{array}$ & $\begin{array}{c}0.0 \\
(0.0-2.5)\end{array}$ & $\begin{array}{c}6.1 \\
(3.2-11.2)\end{array}$ & $\begin{array}{c}0.7 \\
(0.1-3.7)\end{array}$ & $\begin{array}{c}2.7 \\
(1.1-6.7)\end{array}$ & $\begin{array}{c}17.6 \\
(12.3-24.5)(\end{array}$ & $\begin{array}{c}14.9 \\
(10.0-21.5)\end{array}$ & $\begin{array}{c}2.0 \\
(0.7-5.8)\end{array}$ & $\begin{array}{c}4.1 \\
(1.9-8.6)\end{array}$ & $\begin{array}{c}24.3 \\
(18.1-31.8)\end{array}$ & $\begin{array}{c}8.1 \\
(4.7-13.6\end{array}$ & $\begin{array}{c}27.7 \\
(21.1-35.4)\end{array}$ \\
\hline $\begin{array}{l}\text { Mean EPG/OPG* } \\
(\mathrm{CV})\end{array}$ & - & - & - & - & $\begin{array}{c}90 \\
(82 \%)\end{array}$ & $\begin{array}{c}1898 \\
(349 \%)\end{array}$ & $\begin{array}{c}1201 \\
(222 \%)\end{array}$ & $\begin{array}{c}82 \\
(39 \%)\end{array}$ & $\begin{array}{c}137 \\
(169 \%)\end{array}$ & - & - & - \\
\hline
\end{tabular}

* EPG/OPG - eggs/oocysts per $1 \mathrm{~g}$ of faeces.

Table 2. The prevalence of helminth infections in dogs (Canis lupus familiaris Linnaeus) taking into account questionnaire results concerning deworming and preying on rodents.

\begin{tabular}{llccc}
\hline \multirow{2}{*}{ Questionnaire answers } & \multirow{2}{*}{$\begin{array}{c}\text { Number of } \\
\text { dogs }\end{array}$} & \multicolumn{2}{c}{$\%$ of infected dogs $(\mathrm{CI} 95 \%)^{*}$} \\
\cline { 4 - 5 } Preying on rodents & Yes & $43^{1}$ & $9.3(3.7-21.6)$ & $23.3(13.2-37.8)$ \\
& No & 58 & $6.9(2.7-16.4)$ & $25.9(16.3-38.4)$ \\
\hline \multirow{2}{*}{ Deworming } & Yes & $90^{1}$ & $7.8(3.8-15.2)$ & $23.3(15.8-33.1)$ \\
& Yes $(<3 \mathrm{~m})^{* *}$ & 22 & $9.1(2.5-27.8)$ & $22.7(10.1-43.4)$ \\
& No & $58^{1}$ & $8.6(3.7-18.6)$ & $34.5(23.6-47.3)$ \\
\hline
\end{tabular}

* flotation and PCR results were analysed together; $* *$ only dogs dewormed no longer than three months before sampling; ${ }^{1}$ shows that one dog infected with E. multilocularis Leuckart, 1863 is included in this group.

ularis and Taenia spp. Moreover, all the samples were negative for E. granulosus by PCR.

The results of coproscopic examination are presented in Table 1. Overall, helminth eggs were detected in 36 samples $(24.3 \%)$. Taeniid eggs (morphologically identical with those of species of Taenia and Echinococcus) were detected in four dogs $(2.7 \%)$. One of these was the dog positive for E. multilocularis by PCR (only by nested PCR and only in undiluted DNA). The other three samples with taeniid eggs were identified by PCR and sequencing as T. pisiformis (one sample) and T. serialis (two samples). Two of these three samples were positive by PCR both in undiluted and 1:10 diluted DNA, and one only in undiluted DNA.

Besides tapeworms, eggs of nematodes of the following genera were detected: Toxocara Stiles et Hassal, 1905, Toxascaris leonina (von Linstow, 1902) and Trichuris Roederer, 1761 or Capillaria Zeder, 1800. Eggs of Trichuris and Capillaria could not distinguished because of their similar morphology and were counted together. Moreover, oocysts of species of Cystoisospora Frenkel, 1977 were found in six dogs (4.1\%).

According to owners' declarations, 90 of the examined dogs $(61 \%)$ were dewormed (Table 2). Seventy four dogs ( $82 \%$ of dewormed dogs) were treated with combined anthelmintics containing praziquantel, two dogs were treated with a drug not recommended for tapeworms and in 13 cases, no information about the content of anthelmintics was available. Twenty two dogs were treated in the three months prior to sample collection and 68 dogs 3-12 months before sampling. According to owners, 43 dogs had a habit of preying on rodents ( 58 dogs did not prey and the owners of $47 \mathrm{dogs}$ declared that they did not know). One E. multilocularis-positive dog was dewormed (ten months before sampling) and the second one was not treated at all. The same untreated dog was also included in the group of dogs preying on rodents (the owners of the other dog declared that they did not know their dog's preying habits).

Although some differences in prevalence between dewormed and untreated dogs are visible in the general results concerning all helminths, no statistically significant differences were observed.

People. One of the two families whose dogs were E. multilocularis-positive decided to undergo a serological test. Eight persons were examined: four adults (44, 40, 22 and 23 years) and four children (2, 7, 12 and 14 years). None were positive for the presence of $\operatorname{IgG}$ antibodies to Echinococcus spp.

Red foxes. An examination of the intestines of red foxes shot in the area of investigation showed the presence of E. multilocularis in $46 \%$ of these animals. The mean intensity of infection was 1687 tapeworms per fox (range $1-23150, \mathrm{SD}=4535)$.

\section{DISCUSSION}

Two Echinoccocus multilocularis-positive dogs were found in this study. This is the first report of such an infection in dogs living in Poland. An attempt to detect this parasite in dogs was conducted in Poland early in the $21 \mathrm{st}$ century with no positive results (Machnicka-Rowińska et al. 2002). However, these dogs originated from northern and southeastern Polish regions where the prevalence of 
E. multilocularis in red foxes was relatively low (reported to be about $6 \%$ at the time). It can be assumed that the large increase - up to around $50 \%$ according to Karamon et al. (2014) - in the prevalence of E. multilocularis in foxes observed from 2000 to 2013 in the eastern part of Poland may have an impact on prevalence in dogs. This would easily explain the discovery of two positive dogs in this study in contrast to the absence of any cases ten years earlier.

The relatively low values of prevalence in our study are similar to those obtained in other endemic regions in Europe. The broadest cross-sectional study on infection of E. multilocularis (along with E. granulosus and Taenia spp.) in dogs in Europe was conducted by Dyachenko et al. (2008). The authors examined more than 21000 faecal samples from dogs in Germany and some other European countries. They found E. multilocularis-positive dogs only in Germany, with a prevalence of $0.24 \%$. Of the 289 dogs examined in Slovakia, $2.8 \%$ were found to be infected by E. multilocularis - Antolová et al. (2009). Most of the Slovak dogs examined originated from the eastern regions directly bordering our study area. Lithuania is another country bordering Poland where E. multilocularis infected dogs were found: $0.8 \%(2 / 240)$ of village dogs were positive by PCR (Bruzinskaite et al. 2009). Moreover, the major study covering more than 800 dogs in two highly endemic regions of historical focus in eastern France revealed infection by E. multilocularis of $0.5 \%$ of the examined dogs (Umhang et al. 2014). Some of the regions where this infection was investigated in dogs gave no positive results, such as the Netherlands (Maas et al. 2014) and northeastern France, where where 142 and 493 dogs were examined, respectively (Umhang et al. 2012).

Echinococcus granulosus was not detected in any of the dogs examined during this study. Similarly, no tapeworms were found by Dyachenko et al. (2008) in Europe despite examining comprehensive number of samples. Studies in France (Umhang et al. 2014) and the Netherlands (Maas et al. 2014) did not find this tapeworm either. However, in Lithuania, E. granulosus was detected in 3.8\% of dogs (Bruzinskaite et al. 2009). In the present study, one of two E. multilocularis-positive dogs shed taeniid eggs. We were able to assert that these were eggs of E. multilocularis because Taenia spp. was not detected by PCR in this sample. However, the E. multilocularis DNA was detected in the second positive dog (having no detected eggs in the sample) using DNA isolated directly from a faecal sample.

Moreover, this study used a specific approach for detecting E. multilocularis in that we systematically tested copro-DNA samples by two different PCR techniques (one multiplex and one nested) directly on the extracted DNA but also with a 1:10 dilution. One E. multilocularis-positive sample was identified due to the better sensitivity of nested PCR since it was only detected without dilution and not in the multiplex assay. Furthermore, the other E. multilocularis-positive sample was only identified with the $1: 10$ dilution in both PCR assays, like two other taeniid-positive samples during the Taenia PCR assay. It appears important to test diluted copro-DNA samples because the presence of PCR inhibitors are frequently report- ed when analysing such samples. This particular PCR protocol succeeded in increasing the sensitivity of detection, which is of particular interest when focusing on infection with E. multilocularis of dogs where a low prevalence is generally expected. The real-time PCR recently developed by Knapp et al. (2014) may constitute a relevant approach in order to overcome the lack of sensitivity of conventional PCR and enable identification of the potential presence of inhibitors by using an internal control.

The percentage of dogs from the dewormed group that were infected with helminths in general (as well as tapeworms, which were analysed separately) was slightly higher than in the untreated group, but not statistically significant, even though we analysed only dogs dewormed within a three-month-period prior to sampling. This could indicate ineffective drug administration and a potential lack of information for those administering the anthelmintics, whether veterinarians or owners. The inefficacy of deworming dogs was also shown by Sager et al. (2006). The authors revealed that in spite of regular treatment (every three months), the yearly incidence of helminth eggs was relatively high. They showed that there was no significant positive effect of anthelmintic treatment more than twice a year in reducing infections, with the exception of hookworms. Likewise, no or only slight differences were noted by Umhang et al. (2012) between dewormed and untreated dogs. The authors observed a significant decrease in parasitic infection in only one of the two analysed locations and only in dogs treated more than twice a year. Deworming recommendations based on the life cycle of E. multilocularis suggest deworming predisposed dogs (especially those preying on rodents) monthly (Eckert and Deplazes 1999), but such a frequency is difficult for owners to accept.

One of the E. multilocularis-positive dogs in our investigation had a habit of catching rodents. Predation behaviour was estimated as a risk factor of infection with E. multilocularis in the study conducted in Slovakia (Antolová et al. 2009). Umhang et al. (2014) showed the significantly higher prevalence of tapeworm infection in hunting dogs, which have easier access to rodents, resulting in a higher risk of infection.

Owning a dog that killed game or roamed outdoors unattended was identified as a risk factor for alveolar echinococcosis (AE) in humans (Kern et al. 2004). In our study, no positive serological results were found in eight individuals exposed to the infection with E. multilocularis. However, it should be mentioned that due to long incubation period of alveolar echinococcosis in humans, negative results of serological investigations do not definitely mean absence of the disease. Persons that were in direct contact with infected dog should be examined repeatedly to confirm negativity and thus absence of developing disease. Especially because the problem of human AE in Poland is present. From 1990-2011, more than 120 human cases of AE were detected (Nahorski et al. 2013) and new cases have been registered since then (Gołąb and Czarkowski 2014).

This study revealed infection with E. multilocularis of dogs for the first time in Poland. It again shows that the ru- 
ral environment close to human houses in an endemic area of Poland may be contaminated by the eggs of E. multilocularis. The parasite had been previously detected directly in soil (Szostakowska et al. 2014) and indirectly using pigs as an indicator (Karamon et al. 2012). Despite the low prevalence of $E$. multilocularis in rural dogs, they may be an important source of infection for humans due to their close contact.

\section{REFERENCES}

Abbasi I., Branzburg A., Campos-Ponce M., Abdel Hafez S.K., Raoul F., Craig P.S., Hamburger J. 2003: Coprodiagnosis of Echinococcus granulosus infection in dogs by amplification of a newly identified repeated DNA sequence. Am. J. Trop. Med. Hyg. 69: 324-330.

Antolová D., Reiterová K., Miterpaková M., Dinkel A. DUBINSKÝ P. 2009: The first finding of Echinococcus multilocularis in dogs in Slovakia: an emerging risk for spreading of infection. Zoonoses Publ. Hlth. 56: 53-58.

Bruzinskaite R., Sarkunas M., Torgerson P.R., Mathis A., Deplazes P. 2009: Echinococcosis in pigs and intestinal infection with Echinococcus spp. in dogs in southwestern Lithuania. Vet. Parasitol. 160: 237-241.

Dinkel A., von Nickisch-Rosenegk M., Bilger B., Merli M., Lucius R., Romig T. 1998: Detection of Echinococcus multilocularis in the definitive host: coprodiagnosis by PCR as an alternative to necropsy. J. Clin. Microbiol. 36: 1871-1876.

Dyachenko V., Pantchev N., Gawlowska S., Vrhovec M.G., BAUER C. 2008: Echinococcus multilocularis infections in domestic dogs and cats from Germany and other European countries. Vet. Parasitol. 157: 244-253.

ECKert J., DePlazes P. 1999: Alveolar echinococcosis in humans: the current situation in Central Europe and the need for countermeasures. Parasitol. Today 15: 315-319.

Goląв E., Czarkowski M.P. 2014: Echinococcosis and cysticercosis in Poland in 2012. Przegl. Epidemiol. 68: 279-282.

Hegglin D., Deplazes P. 2013: Control of Echinococcus multilocularis: strategies, feasibility and cost-benefit analyses. Int. J. Parasitol. 43: 327-337.

Hofer S., Gloor S., Muller U., Mathis A., Hegglin D., Deplazes P. 2000: High prevalence of Echinococcus multilocularis in urban red foxes (Vulpes vulpes) and voles (Arvicola terrestris) in the city of Zurich, Switzerland. Parasitology 120: $135-142$.

Kapel C.M.O., Torgerson P.R., Thompson R.C.A., Deplazes P. 2006: Reproductive potential of Echinococcus multilocularis in experimentally infected foxes, dogs, raccoon dogs and cats. Int. J. Parasitol. 36: 79-86.

Karamon J. 2014: Detection of Echinococcus multilocularis in faeces by nested PCR with the use of diluted DNA samples. Pol. J. Vet. Sci. 17: 79-83.

Karamon J., Kochanowski M., Dąbrowska J., Sroka J., RóżyCKi M., Bilska-ZAJąC E., CENCEK T. 2015: Dynamics of Echinococcus multilocularis infection in red fox populations with high and low prevalence of this parasite in Poland (20072014). B. Vet. I. Pulawy 59: 213-217.

Karamon J., Kochanowski M., Sroka J., Cencek T., Różycki M., Chmurzyńska E., Bilska-ZająC E. 2014: The prevalence of Echinococcus multilocularis in red foxes in Poland - current results (2009-2013). Parasitol. Res. 113: 317-322.

Karamon J., Sroka J., CenceK T. 2012: The first detection of Echinococcus multilocularis in slaughtered pigs in Poland. Vet. Parasitol. 185: 327-329.

Kern P., Ammon A., Kron M., Sinn G., Sander S., Petersen L.R., GAUS W., KERN P. 2004: Risk factors for alveolar echinococcosis in humans. Emerg. Infect. Dis. 10: 2088-2093.
Knapp J., Millon L., Mouzon L., Umhang G., Raoul F., Ali Z.S., Combes B., Comte S., Gbaguidi-Haore H., GreNouillet F., Giraudoux P. 2014: Real time PCR to detect the environmental faecal contamination by Echinococcus multilocularis from red fox stools. Vet. Parasitol. 201: 40-47.

Maas M., Dam-Deisz W.D.C., van Roon A.M., Takumi K., van DER Giessen J.W.B. 2014: Significant increase of Echinococcus multilocularis prevalence in foxes, but no increased predicted risk for humans. Vet. Parasitol. 206: 167-172.

Machnicka-Rowińska B., Rocki B., Dziemian E., Kolodziej-Sobocinska M. 2002: Raccoon dog (Nyctereutes procyonoides) - the new host of Echinococcus multilocularis in Poland. Wiad. Parazytol. 48: 65-68.

Nahorski W.L., Knap J.P., Pawlowski Z.S., Krawczyk M., Polanski J., Stefaniak J., Patkowski W., Szostakowska B., Pietkiewicz H., Grzeszczuk A., Felczak-KorzybSka I., Golab E., Wnukowska N., Paul M., Kacprzak E., Sokolewicz-Bobrowska E., Niscigorska-Olsen J., Czyrznikowska A., Chomicz L., Cielecka D., Myjak P. 2013: Human alveolar echinococcosis in Poland: 1990-2011. PLoS. Neglect. Trop. Dis. 7: e1986,

OIE 2008: Echinococcosis/hydatidosis. In: Office International des Epizooties (Ed.), Manual of Diagnostic Tests and Vaccines for Terrestrial Animals. Paris, pp. 175-189.

RAYNAUd J.P. 1970: Etude de l'efficacité d'une technique de coproscopie quantitative pour le diagnostic de routine et le controle des infestations parasitaires des bovins, ovins, equins et porcins. Ann. Parasitol. Hum. Comp. 45: 321-342.

Sager H., Moret C.S., Grimm F., Deplazes P., Doherr M.G., Gottstein B. 2006: Coprological study on intestinal helminths in Swiss dogs: temporal aspects of anthelminthic treatment. Parasitol. Res. 98: 333-338.

Szostakowska B., Lass A., Kostyra K., Pietriewicz H., MyJAK P. 2014: First finding of Echinococcus multilocularis DNA in soil: preliminary survey in Varmia-Masuria Province, northeast Poland. Vet. Parasitol. 203: 73-79.

Thompson R.C.A., Kapel C.M.O., Ноbbs R.P., Deplazes P. 2006: Comparative development of Echinococcus multilocularis in its definitive hosts. Parasitology 132: 709-716.

Trachsel D., Deplazes P., Mathis A. 2007: Identification of taeniid eggs in the faeces from carnivores based on multiplex PCR using targets in mitochondrial DNA. Parasitology 134: 911-920.

Umhang G., Comte S., Raton V., Hormaz V., Boucher J.M., Favier S., Combes B., Boue F. 2014: Echinococcus multilocularis infections in dogs from urban and peri-urban areas in France. Parasitol. Res. 113: 2219-2222.

Umhang G., Forin-Wiart M.A., Hormaz V., Caillot C., Boucher J.M., Poulle M.L., Franck B. 2015: Echinococcus multilocularis detection in the intestines and feces of free-ranging domestic cats (Felis s. catus) and European wildcats (Felis $s$. silvestris) from northeastern France. Vet. Parasitol. 214: 75-79.

Umhang G., Raton V., Comte S., Hormaz V., Boucher J.M., Combes B., Boue F. 2012: Echinococcus multilocularis in dogs from two French endemic areas: No evidence of infection but hazardous deworming practices. Vet. Parasitol. 188: 301-305. 